Original Article

\title{
PILL BURDEN, DRUG CLASS DISTRIBUTION AND FINANCIAL BURDEN FOR BUYING MEDICINES IN DIFFERENT MODALITIES OF CHRONIC KIDNEY DISEASE PATIENTS: CROSS- SECTIONAL STUDY
}

\author{
PAVITHRA CIREVALLI' ${ }^{1}$, HARINI DEVI NIMMANAPALLI ${ }^{3 *}$, LALITH KUMAR PARLAPALLI ${ }^{1}$, LAKSHMI SOWJANYA \\ NUTHALAPATI ${ }^{1}$, ANITHA KUTTIAPPAN ${ }^{2}$, SIVA KUMAR VISHNU BHOTLA ${ }^{4}$
}

1Department of Pharmacy Practice, Sree Vidyanikethan College of Pharmacy, Tirupati, India, ${ }^{2}$ Department of Pharmacology, Assistant Professor, Sree Vidyanikethan College of Pharmacy, Tirupati, India, ${ }^{3}$ Department of Biochemistry (MD), Assistant Professor, SVIMS, Tirupati, India, ${ }^{4}$ Department of Nephrology (DM), Senior Professor, SVIMS, Tirupati, India Email: drharinidevi@gmail.com

Received: 21 Mar 2018 Revised and Accepted: 15 May 2018

\section{ABSTRACT}

Objective: The objective of the study was to assess the pill burden (PB), drug class distribution and financial burden for buying medicines in different treatment modalities of chronic kidney disease (CKD) patients.

Methods: A prospective, cross-sectional study was performed in 244 CKD patients and they were divided into 4 groups as follows: pre-dialysis patients (stages 1-5) as group 1, hemodialysis (HD) patients as group 2, peritoneal dialysis (PD) patients as group 3 and renal transplant recipient (RTR) patients as group 4. Data was collected in pre-designed form through direct patient interaction.

Results: Out of 244 CKD patients, PB considering the total number of pills/d in different modalities is $12 \pm 5$ in pre-dialysis, $10 \pm 3$ in $\mathrm{HD}, 13 \pm 5$ in PD, $14 \pm 7$ in RTR and for the number of drug classes/d in different modalities is $7 \pm 3$ in pre-dialysis, $7 \pm 2$ in HD, $8 \pm 3$ in PD and $9 \pm 3$ in RTR. On average mean PB in a number of pills/d is $12 \pm 5$ and number of drug classes/d is $8 \pm 3$. Among all the patients, the RTR individuals are having high medicinal expenditure in comparison to the other modalities.

Conclusion: PB for the number of pills/d is highest in RTR and almost similar in different modalities. Great improvement in reducing the PB as well as financial burden directly or indirectly improves the patient compliance as well as the quality of life.

Keywords: Chronic kidney disease, Pill burden, Drug class distribution, Financial burden, Predialysis, Hemodialysis, Peritoneal dialysis, Renal transplant recipient

(C) 2018 The Authors. Published by Innovare Academic Sciences Pvt Ltd. This is an open access article under the CC BY license (http://creativecommons.org/licenses/by/4.0/) DOI: http://dx.doi.org/10.22159/ijpps.2018v10i6.26186

\section{INTRODUCTION}

Chronic kidney disease (CKD) remains a major global public health problem with increasing prevalence, incidence and tremendous cost with poor outcome [1]. In India, the prevalence rate of CKD was estimated to be $12.5 \%$ [2]. As per global burden of disease study, CKD is estimated to be $12^{\text {th }}$ among all causes of death and men are more prominently affected. In western countries, hypertension (HTN) and diabetes mellitus (DM) was found to be a $2 / 3^{\text {rd }}$ cause of CKD [3]. Likely in India, DM and HTN currently accounted 40-60\% cause of CKD [4]. CKD patients are more prone to high pill burden (PB) because of multiple co-morbidities and indirectly reducing the adherence to therapy.

PB refers to taking more number of pills (tablets or capsules and other conventional dosage forms) that a patient takes on a frequent basis. Therefore, high PB increases the chances of hospitalization, medication errors and elevated costs not only for pharmaceuticals as well as treatment for adverse events [5]. Several studies have reported that dialysis patients are expected to have a high PB due to severe chronic illness combined with multiple co-morbidities. It has been reported that average dialysis patients take 10 to 12 different types of medications [6, 7]. In chronic conditions, complex medication regimens with high PB lead to non-adherence [8-11]. CKD patients are prone to a greater chance of drug-related problems not only by the pharmacokinetic variations in renal excreted drugs but also by the use of more number of medications to manage the complications and co-morbidities in CKD.

In middle and low-income countries, the financial burden is the main concern for the patients who require treatment for dialysis or kidney transplantation. In 2009, the mumbai kidney foundation (MKF) reports gave a perception in end-stage renal kidney disease
(ESRD) cost management stating that each hemodialysis (HD) session in Indian government and corporate hospitals setup would range in between around INR Rs. 150 to Rs. 2000. Annual expenditure for dialysis in India and United States (US) would cost around Rs. 140000 (\$3000) and $\$ 60000$ respectively. Compared to other countries, even though there is less expenditure for dialysis in India, most of the population (90\%) cannot afford it due to economic issues. Whereas kidney transplantation cost ranges from Rs. 50000 in government hospitals and Rs. 300000 in some private hospitals and monthly maintenance for post-transplant drugs would cost around Rs. 10000 (Rs. 120000/y) [12]. Therefore, it is difficult to afford for many people. In CKD, direct healthcare expenditure is greater in patients with anemia than in those without [13] and quality of life issues (ex. fatigue, reduced productivity) are common $[14,15]$. Recently in many Indian hospitals, so many schemes are being implemented. In the present scenario, in many of the states in developing countries, government and non-government organizations have come forward to help the patients in providing subsidized or free dialysis. However, the financial burden for the medicines is variable in CKD patients. Keeping this situation in view, we have undertaken this study to know the drug class distribution, PB and financial burden for buying medicines in CKD patients among different treatment modalities.

\section{MATERIALS AND METHODS}

This was a prospective, cross-sectional study performed in the department of nephrology at Sri Venkateswara Institute of Medical Sciences (SVIMS), a tertiary care teaching hospital, Tirupati for a period of six months from April 2017 to September 2017, which was approved by the institutional ethics committee clearance (622/IEC/2017). A total of 244 patients diagnosed with CKD at all stages were included. Among 
244 CKD patients, based on the modality of treatment, 107 patients were under stage 1-5(pre-dialysis), 58 were in HD, 52 were in peritoneal dialysis (PD) and 27 were in renal transplant recipient (RTR) as per the national kidney foundation/kidney disease outcomes quality initiative (NKF/KDOQI) guidelines [16]. Pregnant women, children below $18 \mathrm{y}$, psychiatric patients and unwilling participants were excluded. Patients information was collected by using a well-designed data collection form which was kept confidential. Patient's information was collected after explaining the study and receiving their consent by using informed consent form. Topical, inhaled, injectable medications were not included in PB.

\section{Study procedure}

Patients were divided into 4 groups as follows: pre-dialysis CKD patients (stages 1-5) as group 1, CKD patients on HD as group 2, CKD patients on PD as group 3 and RTR patients as group 4. The suitable data collection form was used to collect all the necessary information to evaluate PB and financial costs for buying medicines.

\section{Statistical analysis}

All cases information were collected and recorded in microsoft excel sheet. Data were expressed in mean \pm standard deviation (SD). Values were presented as counts and percentage. An unpaired t-test was used to compare between two groups. Comparison across the groups was performed by using one-way ANOVA followed by post hoc analysis. A p value of $<0.05$ was found to be statistically significant.

\section{RESULTS}

The demographic result data were shown in table 1. Out of 244 CKD patients reviewed, $66 \%$ were males and 34\% were females. In male CKD patients, under the age group of $18-59$ y $(n=96)$ constituted $39 \%$ and under the age group of $\geq 60 \mathrm{y}(\mathrm{n}=66)$ constituted $27 \%$ of patients respectively. In female CKD patients, under the age group of 18-59 y $(n=54)$ constituted $23 \%$ and under the age group of 60 y $(n=28)$ constituted $11 \%$ of patients respectively. Dependent CKD patients $(n=100)$ were lesser than independent CKD patients $(n=144)$.

Table 1: Demographic data of study patients

\begin{tabular}{lll}
\hline Demographic data & Males (n) & Females (n) \\
\hline Age in years(y) & & 54 \\
$18-59$ & 96 & 28 \\
$\geq 60$ & 66 & 49 \\
Dependents & 51 & 33 \\
Independents & 111 & \\
Occupational details: & & 37 \\
Agricultural & 38 & 31 \\
Government & 58 & 39 \\
Private & 69 & \\
\hline
\end{tabular}

Based on etiology of CKD, the total patients were divided into two subgroups, i.e., diabetic CKDs and non-diabetic CKDs which include HTN, chronic glomerulonephritis (CGN), chronic interstitial nephritis (CIN) and autosomal dominant polycystic kidney disease
(ADPKD) [table 2]. While comparing occupational status and etiological factors of CKD we found that diabetic CKD patients were more in employment group and non-diabetic CKD (HTN and CGN) patients were more in the agricultural group.

Table 2: Etiology of CKD patients of the present study

\begin{tabular}{|c|c|c|}
\hline Etiology & No. of patients(n) & Percentage (\%) \\
\hline $\mathrm{DM}$ & 103 & 42 \\
\hline HTN and CGN & 117 & 48 \\
\hline CIN & 19 & 8 \\
\hline ADPKD & 5 & 2 \\
\hline
\end{tabular}

DM-diabetes mellitus, HTN-hypertension, CGN-chronic glomerulonephritis, CIN-chronic interstitial nephritis, ADPKD-autosomal dominant polycystic kidney disease

One-way ANOVA followed by post hoc bonferroni analysis was performed to assess the drug classes and the number of pills/d in different modalities and unpaired t-test was performed to assess PB in different modalities between the age group 18-59 y and $\geq 60$ y [table 3]. When compared with other modalities, mean PB for drug classes/d was found to be highest $(9 \pm 3)$ and mean PB for a total number of pills

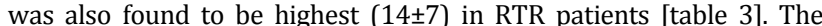
results showed that there was no significance between mean pills/d among different modalities between the age group $18-59 \mathrm{y}$ and $\geq 60 \mathrm{y}$ except in PD patients which showed significance $\left(\mathrm{p}=0.002^{*}\right)$ and for drug classes/d also showed no significance between age groups except in HD which showed significance $\left(\mathrm{p}=0.013^{*}\right)$.

Table 3: Mean pill burden for number of pills and drug classes per day across different modalities

\begin{tabular}{|c|c|c|c|c|c|c|c|c|}
\hline Modalities & Age & $\mathbf{N}$ & Drug classes/d & p value & p value vs pre-dialysis & Total pills/d & p value & p value vs pre-dialysis \\
\hline \multirow[t]{3}{*}{ Pre-dialysis } & 18-59 & 48 & $7 \pm 3$ & & & $13 \pm 5$ & & \\
\hline & $\geq 60$ & 59 & $7 \pm 2$ & & & $12 \pm 4$ & & \\
\hline & mean & $54 \pm 5$ & $7 \pm 3$ & $1.000^{\dagger}$ & & $12 \pm 5$ & $0.252^{\dagger}$ & \\
\hline \multirow[t]{3}{*}{ HD } & $18-59$ & 39 & $7 \pm 1$ & & $0.160^{\dagger}$ & $11 \pm 2$ & & $0.426 \dagger$ \\
\hline & $\geq 60$ & 19 & $8 \pm 2$ & & & $10 \pm 3$ & & \\
\hline & mean & $29 \pm 10$ & $7 \pm 2$ & $0.013^{*}$ & & $10 \pm 3$ & $0.136^{\dagger}$ & \\
\hline \multirow[t]{3}{*}{ PD } & $18-59$ & 36 & $8 \pm 3$ & & $0.934^{\dagger}$ & $14 \pm 5$ & & $0.939 \dagger$ \\
\hline & $\geq 60$ & 16 & $7 \pm 2$ & & & $10 \pm 1$ & & \\
\hline & mean & $26 \pm 10$ & $8 \pm 3$ & $0.102^{\dagger}$ & & $13 \pm 5$ & $0.002^{*}$ & \\
\hline \multirow[t]{4}{*}{ RTR } & $18-59(\mathrm{M})$ & 20 & $9 \pm 2$ & & $0.185^{\dagger}$ & $14 \pm 5$ & & $0.228^{\dagger}$ \\
\hline & $18-59(F)$ & 07 & $9 \pm 4$ & & & $16 \pm 11$ & & \\
\hline & $\geq 60$ & 0 & & & & & & \\
\hline & mean & & $9 \pm 3$ & $1.000^{\dagger}$ & & $14 \pm 7$ & $0.517^{\dagger}$ & \\
\hline
\end{tabular}

Data are given as number (n) of patients, values expressed in mean \pm standard deviation, Significant at *p $<0.05$ probability level, ${ }^{\dagger} \mathrm{NS}$-not significant at the 0.05 probability level, p-value by using one-way ANOVA between age groups and p-value vs pre-dialysis using post hoc bonferroni analysis between different modalities., Abbreviations: HD-hemodialysis, PD-peritoneal dialysis, RTR-renal transplant recipient 
Across different modalities, the PB for different classes of medications was shown in fig. 1. The unpaired t-test was used to find the significant difference between different drug classes of medications and mean pills/d in HD and PD [table 4]. It was observed that there was a statistically significant between different drug classes of medications and mean pills/d in HD and PD $\left(\mathrm{p}<0.05^{*}\right)$.

Table 4: Pill burden in HD and PD

\begin{tabular}{llllllll}
\hline Age & HD & PD & Drug classes/d & Drug classes/d & p value & $\begin{array}{l}\text { Total pills/d } \\
\text { (HD) }\end{array}$ & $\begin{array}{l}\text { Total pills/d } \\
\text { (PD) }\end{array}$ \\
\hline $18-59$ & 39 & 36 & $7 \pm 1$ & $8 \pm 3$ & $0.007^{*}$ & $11 \pm 2$ & $14 \pm 5$ \\
$\geq 60$ & 19 & 16 & $8 \pm 2$ & $7 \pm 2$ & $0.033^{*}$ & $10 \pm 3$ & $10 \pm 1$ \\
& & Mean & $7 \pm 2$ & $8 \pm 3$ & $0.033^{*}$ & $10 \pm 3$ & $13 \pm 5$ \\
\hline
\end{tabular}

${ }^{*} \mathrm{p}<0.05$ is considered statistically significant (unpaired t-test), ${ }^{\dagger}$ NS-Not significant at the 0.05 probability level, data are given as number (n) of patients, values expressed in mean \pm standard deviation, Abbreviations: HD-hemodialysis, PD-peritoneal dialysis

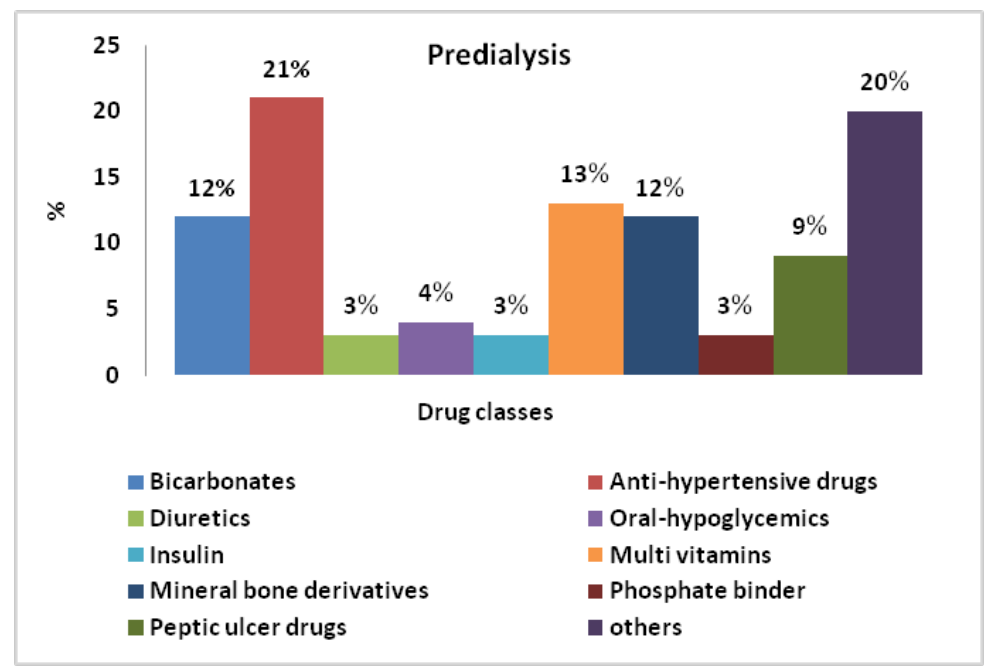

Fig. 1a: Drug class distribution in predialysis

Fig 1a. Others include: CAD, hyperlipidemic drugs, hypothyroidism drugs, hyperthyroidism drugs, anti-emetic drugs, laxatives, hematinics, uric acid inhibitors, COPD (rare patients).

Abbreviations: coronary artery disease (CAD), chronic obstructive pulmonary disease (COPD)
Fig 1b. Others include: CAD, hyperlipidemic drugs, hypothyroidism drugs, anti-emetic drugs, laxatives, hematinics, uric acid inhibitors, COPD (rare patients)

Abbreviations: coronary artery disease (CAD), chronic obstructive pulmonary disease (COPD)

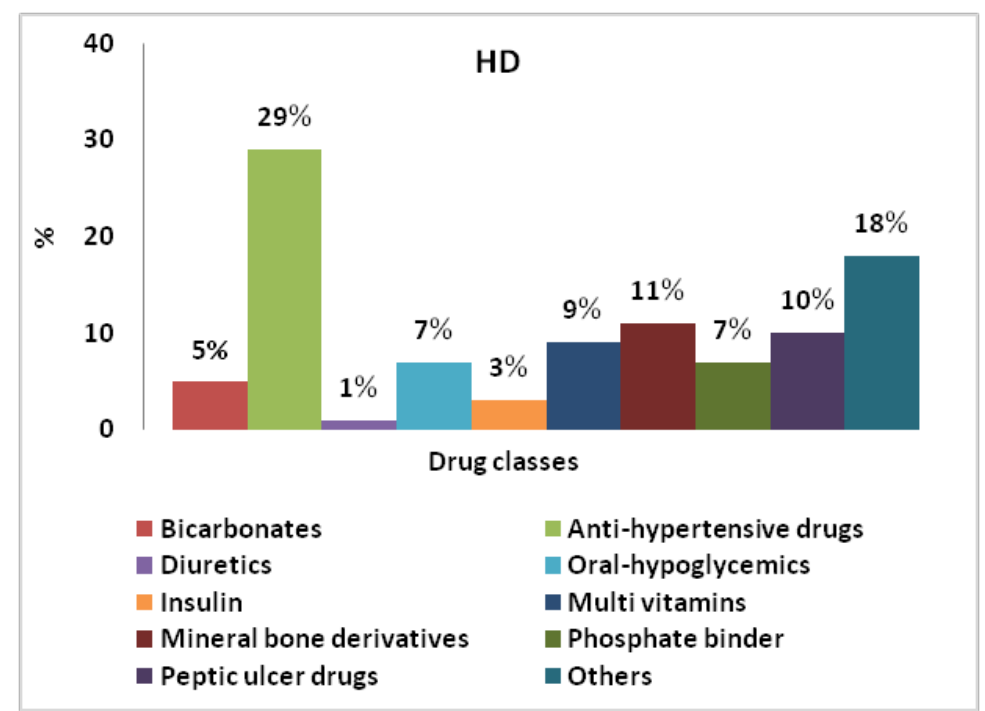

Fig. 1b: Drug class distribution in HD 


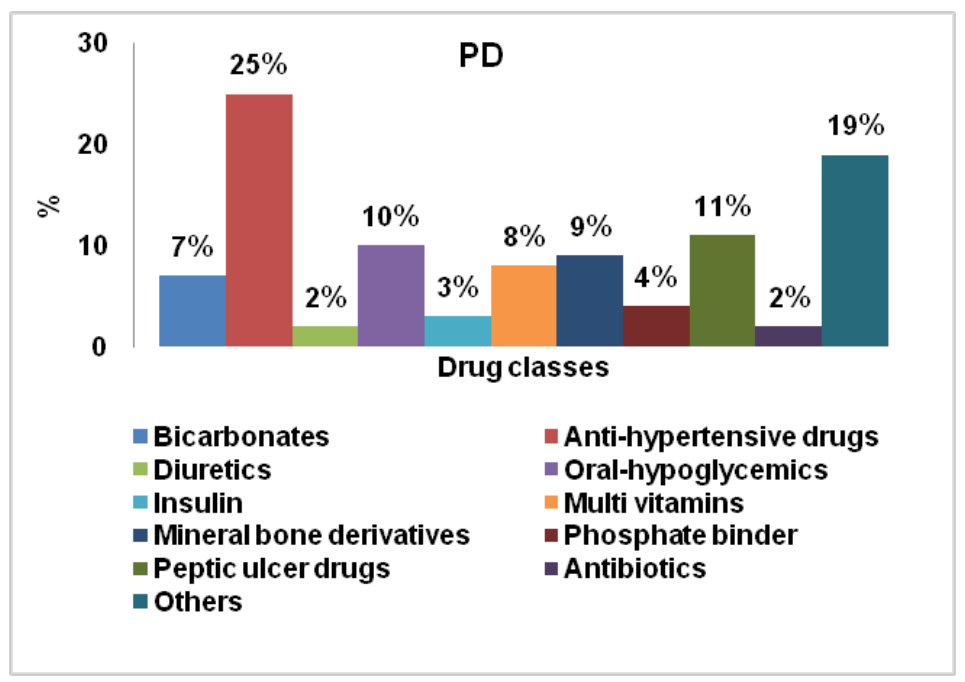

Fig. 1c: Drug class distribution in PD

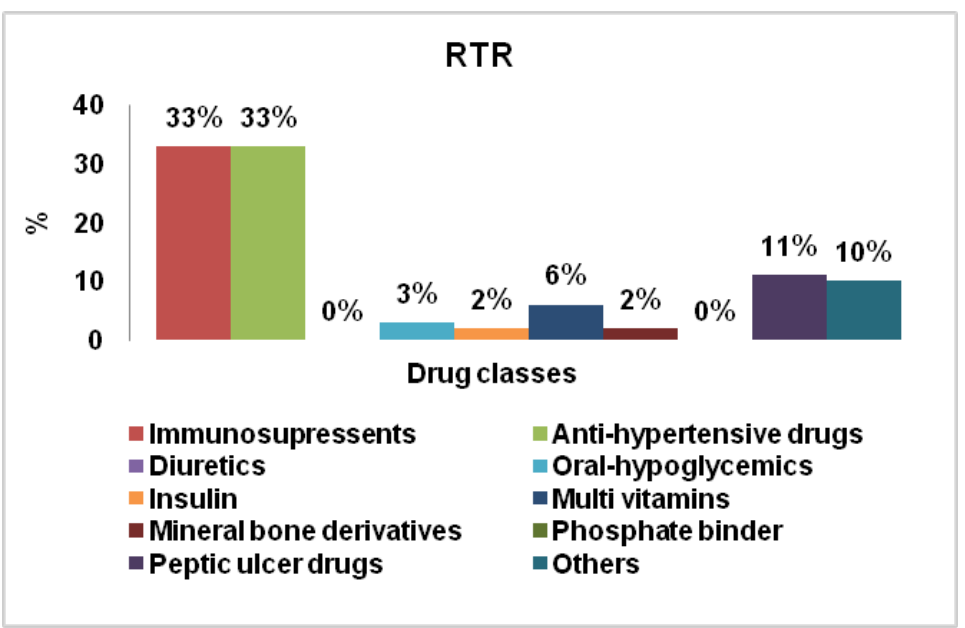

Fig. 1d: Drug class distribution in RTR

Fig 1c. Others include: CAD, hyperlipidemic drugs, hypothyroidism drugs, anti-emetic drugs, laxatives, hematinics, uric acid inhibitors, COPD (rare patients)

Abbreviations: Coronary artery disease (CAD), chronic obstructive pulmonary disease (COPD)

Immunosuppressants include prednisolone, mycophenolate mofetil, tacrolimus, sirolimus,
Fig 1d.Others include: CAD, hyperlipidemic drugs, hypothyroidism drugs, hematinics, antibiotics, COPD (rare patients)

Abbreviations: coronary artery disease (CAD), chronic obstructive pulmonary disease (COPD)

Average monthly medicinal expenditure for the CKD patients among different modalities was shown in table 5 . The results showed that, in CKD patients, RTR patients were found to have the highest cost for buying medicines when compared to other modalities.

Table 5: Average monthly medicinal expenditure for buying pills in CKD patients between the modalities

\begin{tabular}{|c|c|c|c|c|c|c|c|}
\hline Modalities & $\begin{array}{l}\text { Average medicinal } \\
\text { expenditure (in rupees) }\end{array}$ & $\begin{array}{l}\text { p-value (pre- } \\
\text { dialysis vs HD) }\end{array}$ & $\begin{array}{l}\text { Pre-dialysis vs } \\
\text { PD }\end{array}$ & $\begin{array}{l}\text { Pre-dialysis vs } \\
\text { RTR }\end{array}$ & $\begin{array}{l}\text { HD vs } \\
\text { PD }\end{array}$ & $\begin{array}{l}\text { HD vs } \\
\text { RTR }\end{array}$ & $\begin{array}{l}\text { PD vs } \\
\text { RTR }\end{array}$ \\
\hline Pre dialysis & $2270 \pm 1000$ & $0.634^{\dagger}$ & $0.848^{\dagger}$ & $0.001 *$ & & & \\
\hline HD & $2195 \pm 900$ & $0.634^{\dagger}$ & & & $0.510^{\dagger}$ & $0.001^{*}$ & \\
\hline PD & $2300 \pm 750$ & & $0.848^{+}$ & & $0.510^{\dagger}$ & & $0.001^{*}$ \\
\hline RTR & $5200 \pm 2060$ & & & $0.001 *$ & & $0.001^{*}$ & $0.001 *$ \\
\hline
\end{tabular}

${ }^{*} \mathrm{p}<0.05$ is considered statistically significant (one-way ANOVA), ${ }^{\dagger}$ NS-not significant at the 0.05 probability level, values expressed in mean \pm standard deviation (SD), Abbreviations: HD-hemodialysis, PD-peritoneal dialysis

\section{DISCUSSION}

Globally, CKD is becoming a major health problem for the public.
Thus, patients with CKD are an ideal target for interventions aimed at reduction of morbidity and mortality. This study focused on drug classes, daily total PB and financial burden for buying medicines in different modalities in CKD patients. 
CKD management contributes to significant financial burden together on health systems, patients and their households. In developing countries, such as India, kidney failure cases were increased mainly in the elderly populations [17]. In middle-income countries, the financial burden is the major concern for the people who require treatment for dialysis or kidney transplantation. In patients with CKD belonging to low-income countries, the morbidity and mortality rate per annum found to be high as they cannot be able to afford the treatment for kidney failure [18].

This present study data showed that CKD burden was more in the age group 18-59 y when compared to age group60 y and males were more predominant than females. The etiological factor in CKD found to be DM followed by HTN, CGN, CIN and ADPKD. We found diabetic CKD was more in the employed group while non-diabetic CKD (HTN and CGN) was more in the agricultural group. Female CKD patients found to be more dependent than males. In our study, based on the modality of treatment majority of the CKD patients belong to stage 1-5 (pre-dialysis). Comorbid conditions such as cardiovascular disease (CVD), ischemic heart disease (IHD) and peripheral artery disease (PAD) have shown to be associated with increased hospitalizations among ESRD $[19,20]$ and pre-dialysis patients [21] that might enhance the financial burden in these populations. Multiple factors play a key role in adherence to pharmacological therapy in CKD population. One of the barriers to non-adherence is a financial burden in this population. The link between PB to adherence and outcomes is an important role for the general population in clinical practice setting [22].

This study was focused to find out the extent of PB on patients belonging to various stages of CKD on different treatment modalities including pre-dialysis, HD, PD, post-transplant groups (RTR). With regard to $\mathrm{PB}$, represented as number of pills/d we observed that it was $12 \pm 5$ in pre-dialysis, $10 \pm 3$ in HD, $13 \pm 5$ in PD, $14 \pm 7$ in RTR and we did not find any statistical difference but when compared with age groups (18-69 y and $\geq 60 \mathrm{y}$ ) also showed no significance except in PD patients. With regard to different drug classes/d, we observed that it was $7 \pm 3$ in pre-dialysis, $7 \pm 2$ in $\mathrm{HD}, 8 \pm 3$ in PD, $9 \pm 3$ in RTR and we did not find any statistical difference but when compared with age groups (18-69y and $\geq 60 \mathrm{y}$ ) also showed no significance except in HD patients. Our observation suggests that the average $P B$ in the number of pills/d is $12 \pm 5$ (7-17 pills/d) and average PB in the number of drug classes/d is $8 \pm 3$ (5-11 drug classes/d) among different modalities. A similar study was conducted in the year 2009 by Kathrine Parker et al., in the US and their study reported that HD patients had a significantly lower PB (11 \pm 7 pills/d) compared with PD patients(16 \pm 7 pills/d) [23]. A similar study was conducted in the year 2011-2012 by Uma Rani Adhikari et al., in two tertiary care hospitals, Kolkata who were running renal transplant program, their study mean PB ranged between 10-21 pills/d [24]. The pharmacological therapy varies with an average number of medicines given to different modalities. In the present study, it was found that there is a significant difference $\left({ }^{*} p<0.05\right)$ observed in average drug classes/d and average pills/d between HD and PD.

In addition to the medications that are taken in pre-dialysis, HD and PD patients, the RTR patients require immunosuppressant's and anti-hypertensive drugs followed with other medications which are required for them were given that might contribute to more number of pills/d compared to other modalities. Majority of post renal transplantation medication include triple immunosuppressive i.e., prednisolone, mycophenolate mofetil, tacrolimus or sirolimus. Sirolimus usage was limited to patients from whom from tacrolimus was been removed for medical reasons. In a study by Kathrine Parker et al., also reported that more number of RTR patients consumes anti-hypertensive medications and hence observed more burden to consume medications in this group [23].

With regard to financial burden in the present study, all the patients were been supported for dialysis treatment indicating that there was no expenditure from the patients towards dialysis procedure. However, the financial burden for the medicinal expenditure was variable. The CKD patients on RTR were been found to have financial burden when compared to other modalities. Thus, from the present study it was observed that all the CKD patients were financially being supported completely for dialysis. Henceforth if likely extension of the similar support for the provision of drugs for all the CKD patients in various stages can be considered to reduce the burden on pharmaceutical costs not only for the patients but also to the caregivers of the family which increases the adherence to medications. On a cross-sectional study basis, a onetime impromptu expression on approximate expenditure they incur on monthly basis for the drugs was been considered. However, the patients do receive support in the form of reimbursement in certain of the categories and supports from charity organizations for some categories. Therefore, the information provided on the expenditure is an approximate figure.

\section{CONCLUSION}

From the present study, we conclude that the monthly medicinal costs in CKD patients with pre-dialysis, HD and PD were variable. It is observed that the CKD patients on RTR were having high financial burden/costs for medicines. Thus, measures to provide free medicines or subsidized medicines might be considered that reduce the pharmaceutical costs and increases the adherence to therapy. Keeping this observation in view in order to reduce $P B$, the practice of prescribing fixed drug dose combinations, extended release or sustained release formulations and the drugs with long-acting agents and prescribing medicines based on their absolute indication can be the logical strategies to reduce the pill number and also drug classes. In addition to above, the practice of prescribing utilization of generic drugs may significantly reduce the expenditure on drugs, which ultimately reduce the financial burden. An additional support of Rs. 3000 to 5000 per patient would help in relieving their financial burden and indirectly encouraging them to utilize the savings to be used for family support, compliance to therapy, better nutritional support and reducing the financial burden on a patient. This understanding would help the supporting organizations to include a fiscal consideration while planning policy issues to meet the disease treatment requirements holistically.

\section{Limitation of the study}

The main limitation of the present study was that it was been carried out only for a short duration. Adherence was not studied which remains the main problem in chronic condition patients, especially with large PB. Another main limitation was that not all healthcare cost components were included in the present study.

\section{ABBREVIATION}

chronic kidney disease (CKD), hypertension (HTN), diabetes mellitus (DM), pill burden (PB), national kidney foundation/kidney disease outcomes quality initiative (NKF/KDOQI), hemodialysis (HD), peritoneal dialysis (PD), renal transplant recipient (RTR), mumbai kidney foundation (MKF), end-stage renal kidney disease (ESRD), chronic glomerulonephritis (CGN), chronic interstitial nephritis (CIN), autosomal dominant polycystic kidney disease (ADPKD).

\section{ACKNOWLEDGEMENT}

The authors would like to thank Dr. Ram, nephrology HOD, other staff in nephrology department SVIMS for their help and guidance and to the principal of Sree Vidyanikethan College of Pharmacy.

\section{AUTHORS CONTRIBUTIONS}

1. Cirevalli Pavithra had contributed in concepts, design, the definition of intellectual content, literature search, data acquisition, data analysis, statistical analysis, manuscript preparation, manuscript editing, manuscript review.

2. Harini Devi. N, had contributed in concepts, definition of intellectual content, literature search, statistical analysis, manuscript preparation, manuscript editing, manuscript review.

3. Parlapalli Lalith kumar, had contributed in concepts, design, definition of intellectual content, literature search, data acquisition, data analysis, statistical analysis.

4. Nuthalapati Lakshmi Sowjanya, had contributed in concepts, design, definition of intellectual content, literature search, data acquisition, data analysis, statistical analysis. 
5. Kuttiappan Anitha had contributed in concepts, design, definition of intellectual content, literature search.

6. Dr. V. Siva kumar, had contributed in concepts, design, definition of intellectual content, manuscript editing, manuscript review.

\section{CONFLICT OF INTERESTS}

\section{Declared none}

\section{REFERENCES}

1. Eknoyan G, Lameire N, Barsoum R, Eckardt UK, Levin A, Levin $\mathrm{N}$, et al. The burden of kidney disease: improving global outcomes. Kidney Int 2004;66:1310-4.

2. Jessani S, Bux R, Jafar TH. Prevalence, determinants, and management of chronic kidney disease in Karachi, Pakistan-a community based cross-sectional study. BMC Nephrol 2014;15:90.

3. Snyder S, Pendergraph B. Detection and evaluation of chronic kidney disease. Am Fam Physician 2005;72:1723-32.

4. Rajapurkar MM, John GT, Kirpalani AL, Abraham G, Agarwal SK, Almeida AF, et al. What do we know about chronic kidney disease in India: the first report of the Indian CKD registry. BMC Nephrol 2012;13:10.

5. Kumar U, Srikar N. Role of the pharmacist in medical error and medication adherence. Indian J Pharm Sci Res 2012;2:84-92.

6. The USRDS Dialysis Morbidity and Mortality Study: Wave 2. United States Renal Data System. Am J Kidney Dis 1997;30:S67-85.

7. Manley HJ, Garvin CG, Drayer DK, Reid GM, Bender WL, Neufeld $\mathrm{TK}$, et al. Medication prescribing patterns in ambulatory hemodialysis patients: comparisons of USRDS to a large notfor-profit dialysis provider. Nephrol Dial Transplant 2004;19:1842-8.

8. Haynes RB, Ackloo E, Sahota N, McDonald HP, Yao X. Interventions for enhancing medication adherence. Cochrane Database Systematic Reviews 2008.

9. Neri L, Martini A, Andreucci VE, Gallieni M, Rey AL, Brancaccio $\mathrm{D}$, et al. Regimen complexity and prescription adherence in dialysis patients. Am J Nephrol 2011;34:71-6.

10. Ingersoll KS, Cohen J. The impact of medication regimen factors on adherence to chronic treatment: a review of the literature. J Behav Med 2008;31:213-24.
11. Recker RR, Gallagher R, Mac Cosbe PE. Effect of dosing frequency on bisphosphonate medication adherence in a large longitudinal cohort of women. Mayo Clin Proc 2005; 80:856-61.

12. Khanna U. The Economics of Dialysis in India. Indian J Nephrol 2009;19:1-4.

13. Smith RE Jr. The clinical and economic burden of anemia. Am J Manag Care 2010;16:S59-66.

14. Elsayed AS, Azab AE. Correlation between chronic kidney diseases and hematolgical data in Sabratha hospital in Libya. Asian J Pharm Clin Res 2017;10:291-6.

15. Van Nooten FE, Green J, Brown R, Finkelstein FO, Wish J. Burden of illness for patients with non-dialysis chronic kidney disease and anemia in the United States: a review of the literature. J Med Econ 2010;13:241-56.

16. National Kidney Foundation: K/DOQI clinical practice guidelines for chronic kidney disease: Evaluation, classification and stratification. Am J Kidney Dis 2002;39 Suppl 1:S1-266.

17. Jha V, Garcia GG, Iseki $\mathrm{K}$, Li Z, Naicker $\mathrm{S}$, Plattner $\mathrm{B}$, et al. Chronic kidney disease: global dimension and perspectives. Lancet 2013;382:260-72.

18. Couser WG, Remuzzi G, Mendis S, Tonelli M. The contribution of chronic kidney disease to the global burden of major noncommunicable diseases. Kidney International 2011;80:1258-70.

19. Arora P, Kausz A, Obrador G, Ruthazer R, Khan S, Jenuleson CS, et al. Hospital utilization among chronic dialysis patients. J Am Soc Nephrol 2000;11:740-6.

20. Rocco MV, Soucie MJ, Reboussin DM, Mc Clellan WM. Risk factors for hospital utilization in chronic dialysis patients. J Am SocNephrol 1996; 7:889-96.

21. Holland DC, Lam M. Predictors of hospitalization and death among pre-dialysis patients: a retrospective cohort study. Nephrol Dial Transplant 2000;15:650-8.

22. Hirth RA, Greer SL, Albert JM, Young EW, Piette JD. Out-OfPocket spending and medication adherence among dialysis patients in twelve countries. Health Aff 2008;27:89-102.

23. Kathrine Parker, Milind Nikam, Anuradha Jayanti and Sandip Mitra. Medication burden in CKD-5D: impact of dialysis modality and setting. Clinical Kidney Journal 2014;7:557-61.

24. Adhikari UR, Taraphder A, Hazra A,Das T. Pill burden does not influence compliance with oral medication in recipients of renal transplant. Indian Journal of Pharmacology 2016;48:21-5. 